\title{
Farklı Sınıf Çimento Harcı Üretiminde Metakaolin Katkısı Kullanımının Araştırılması
}

\author{
Gökhan Görhan ve Gökhan Kürklü \\ Afyon Kocatepe Üniversitesi, Mühendislik Fakültesi, İnşaat Mühendisliği Bölümü, Afyonkarahisar
}

ggorhan@aku.edu.tr

\begin{abstract}
Özet- Bu çalışmada, metakaolin ikameli ve farklı dayanım sınıfına ait portland çimentolu harçların fiziksel ve mekanik özellikleri araştırılmıştır. Harç örneklerinin üretiminde; CEM II/B-M 32.5 R (A çimentosu) ve CEM I 42.5 R (B çimentosu) olmak üzere iki farklı portland çimentosu kullanılmıştır. Çimentoya ikame edilecek olan metakaolin ise, laboratuvar şartlarında ve kaolin kilinin beş farklı sıcaklıkta $(600,700,800$, 900 ve $1000{ }^{\circ} \mathrm{C}$ ) sinterlenmesi sonucunda elde edilmiştir. Sinterlenen metakaolin örneklerine 7 günlük puzolanik aktivite deneyleri yapılmış ve en yüksek puzolanik aktivite indeksi, 900 ${ }^{\circ} \mathrm{C}$ 'de sinterlenen örneklerde elde edilmiştir. Ardından hazırlanan karışımlarda çimentoya, $900{ }^{\circ} \mathrm{C}$ 'de sinterlenen metakaolin malzemesi \% 10 ve \% 20 oranlarında ikame edilmiş ve referans çimento harçları ile kıyaslanmıştır. Harç üretiminde standart kum kullanııış olup örnekler, TS EN 196-1 nolu standarda göre

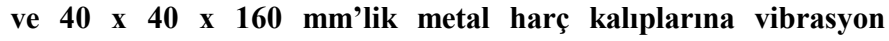
yöntemiyle yerleştirilmiştir. Daha sonra örneklere 7 ve 28 günlük su kürü uygulanmıştır. Kür işlemi tamamlanan örneklere; su emme, porozite, birim hacim ağırlık ve görünür yoğunluk gibi fiziksel testler ile eğilme dayanımı ve basınç dayanımı gibi mekanik testler yapılmıştır. Bununla birlikte örneklerin ultrases değerleri de belirlenerek çimento harcı üretiminde kullanılan metakaolin katkısının örnekler üzerinde meydana getirdiği değişiklikler araştırılmıştır. Sonuç olarak, A çimentosu ile \% 20 MK ve B çimentosu ile \% 10 MK malzemelerinin bir arada kullanılması durumunda örneklerden en yüksek basınç dayanım değerleri elde edilmiştir.
\end{abstract}

Anahtar Kelimeler- Çimento, metakaolin, standart kum, sinterleme, kaolin.

Abstract- In this study, it was studied physical and mechanical properties of Portland cement mortars with different strength classes and metakaolin (MK) substituted. Two different Portland cement such as CEM II/B-M 32.5 R (A cement) and CEM I 42.5 $R$ (B cement) is used in the production of mortar samples. Metakaolin which is substituted by cement was obtained as a result with sintering of kaolin clay in five different temperatures $\left(600,700,800,900\right.$ ve $\left.1000{ }^{\circ} \mathrm{C}\right)$ in the laboratory conditions. 7-day sintered metakaolin samples were conducted pozzolanic activity test and the highest pozzolanic activity index was obtained in the samples sintered at $900{ }^{\circ} \mathrm{C}$. Then, it was substituted at a rate of $10 \%$ and $20 \%$ metakaolin material sintered $900{ }^{\circ} \mathrm{C}$ and it was compared with the reference cement mortar. Standard sand was used in the production and the samples were placed with vibration method in $40 \times 40 \times 160 \mathrm{~mm}$ metal mould according to TS EN 196-1. Later, 7 and 28 days water cure is applied to samples. Finally, the physical tests such as water absorption, porosity, bulk density and apparent density with the mechanical properties such as flexural strength and compressive strength were determinated. However, the ultrasound values were determinated from the samples. As a result, the highest compressive strength values were obtained from the samples with $20 \%$ MK together A cement and $10 \%$ MK together B cement.

Index Terms - Cement, metakaolin, standard sand, sintering, kaolin.

\section{GİRİŞ}

Cimento harcı üretiminde kullanılan puzolanlardan biri de $\zeta$ metakaolindir. Metakaolin (MK), kaolin kilinin belirli sicaklıklarda sinterlenmesi sonucu oluşan yapay bir puzolandır. Kaolin, esasen bir kil mineralidir ve sahip olduğu kristal yapısı nedeniyle kaolenit grubu içerisinde yer alır. Kaolin $\left(\mathrm{Al}_{2} \mathrm{Si}_{2} \mathrm{O}_{5}(\mathrm{OH})_{4}\right)$, kil mineralleri sinıflandırmasinda bir grup kil minerali ismidir. Bu grupta kaolinit'in dişında; dikit, nakrit ve halloisid gibi mineraller bulunmaktadır. Oluşum itibariyle, feldspat içeren granitik veya volkanik kayaçların feldspatlarının altere olarak kaolinit mineraline dönüşmesi sonucu kaolinler oluşmaktadır. Ana kayaç içindeki alkali ve toprak alkali iyonların, çözünür tuzlar şeklinde ortamdan uzaklaşması sonucu $\mathrm{Al}_{2} \mathrm{O}_{3}$ içerikli, sulu ve silikatça zenginleşen kayaç kaoliniti oluşturur [1].

Çimento üretimlerinde MK gibi puzolanlar çok sık kullanılmaktadır. Katkı malzemesi olarak kullanılarak puzolanlar elde edildikleri kaynaklara göre doğal veya yapay puzolan olarak adlandırılırlar. Doğal puzolanlar silisli ve alüminli bileşiklerle zengindir. Puzolanlar için silisli ve alüminli minerallerin türü ve miktarı puzolanik aktivite üzerinde önemli rol oynamaktadır [2]. Puzolanik aktivite, çimentolu üretimlerde kalsiyum hidroksit ve puzolandaki alüminosilikatlar arasındaki reaksiyonun hızı ve kapasitesi olarak tanımlanmaktadır. Bununla birlikte; puzolanın " $\mathrm{SiO}_{2}+$ $\mathrm{Al}_{2} \mathrm{O}_{3}+\mathrm{Fe}_{2} \mathrm{O}_{3}$ " içeriği, amorf faz durumu ve malzemenin inceliği puzolanik aktiviteyi etkilemektedir [3]. 
Son yıllarda yüksek dayanımlı betonların ve harçların üretiminde başta olmak üzere birçok farklı uygulamalarda metakaolin kullanılmaktadır. Metakaolin $\left(\mathrm{Al}_{2} \mathrm{O}_{3} \cdot 2 \mathrm{SiO}_{2}\right)$, saflaştırılmış kaolin kilinin $\quad 650-800 \quad{ }^{\circ} \mathrm{C}$ arasındaki sicakliklarda sinterlenmesi sonucu elde edilen ve genellikle beyaz renkte olan bir üründür. Kaolin kili $200^{\circ} \mathrm{C}$ 'de 1sitıldığında adsorbe suyunu kaybederken, $500-600^{\circ} \mathrm{C}$ isitmada kimyasal bağ suyunu kaybederek MK'e, $1000{ }^{\circ} \mathrm{C}$ isitmada ise mullit ve kristobalite dönüşmektedir. Uygulanan bu sinterleme işlemi sonucunda MK bünyesindeki kristal yapılarda bozulma gerçekleşerek amorf yapılı ve yüksek puzolanik özellikli bir yapıya kavuşur. MK yapısında bulunan yüksek oranlı silis ve alümin ile birlikte çimento hidratasyonu sonucu ortaya çıkan $\mathrm{Ca}(\mathrm{OH})_{2}$ ile reaksiyona girerek yeni C-S-H yapıları oluşturur. $\mathrm{Bu}$ ürünler sayesinde beton veya harçlarda mekanik özelliklerde artışlar görülür $[4,5]$.

Literatürde konu ile ilgili yapılmış çalışmalara göre; Caldarone vd. [6] su/bağlacı oranı 0.40 olan karışımlarda MK malzemesini $\% 5$ ve $\% 10$ oranlarında kullanmış ve sonuç olarak \% 5 MK katkılı örneklerde 78.3 MPa basınç dayanım değerleri elde etmiştir. Curcio vd. [7] yaptıkları çalışmada ise su/bağlayıcı oranı 0.33 olan harçlar üretmiş̧tir. Elde edilen verilere göre erken yaşlarda MK katkılı harçların dayanım kazanma hızının yüksek olduğu belirtilmiştir. MK katkılı harçların erken dayanım kazanmasında $\mathrm{Al}_{\mathrm{lv}} \mathrm{ve} \mathrm{Al}_{\mathrm{v}}$ olmak üzere iki farklı $\mathrm{Al}_{2} \mathrm{O}_{3}$ içeriği olmasına bağlanmış ve alümina içeren fazların oluşumunun (özellikle $\mathrm{C}_{2} \mathrm{ASH}_{8}$ ) erken dayanımı arttırdığ belirtilmiştir. Qian ve Li [8], \% 0, 5, 10 ve \% $15 \mathrm{MK}$ içerikli betonlar hazırlamıştır. Betonlarda kullanılan MK katkı oranlarının artmasıyla çekme ve eğilme dayanımlarının arttığını belirtmiştir. Courard vd. [9] çalışmalarında çimentoya $\% 5-20$ aralığında MK katkısı yapmıştır. MK katkılı örneklerin eğilme dayanımlarının 7. günde referans örneklerle benzer değerler verdiği, 14 ve 28 günlük örneklerde ise MK katkılı örneklerin daha yüksek eğilme dayanım değerleri verdiğini belirtmiştir [5].

Yapılan bu çalışmada ise literatürden farklı olarak kaolin kili laboratuvar koşullarında farklı sıcaklıklarda kalsine edilmiştir. Ardından kısa dönem içinde en yüksek reaktiflik gösteren sinterleme sıcaklığı baz alınmış ve elde edilen MK malzemesinin iki tip çimentoya ikame edilmesi durumunda örneklerde meydana getirdiği değişiklikler araştırılmıştır.

\section{MATERYAL VE METOT}

\section{Kullanılan Malzemeler}

Örneklerin üretiminde CEM II/B-M (P-LL) $32.5 \mathrm{R}$ (A çimentosu) ve CEM I $42.5 \mathrm{R}$ (B çimentosu) tipi olmak üzere iki farklı sınıf çimento kullanılmıştır. Çimentoya ikame edilen metakaolin (MK) ise Türkiye'de bulunan özel işletmeli bir seramik fabrikasından elde edilen kaolin kilinin laboratuvar koşullarında sinterlenmesi sonucu elde edilmiştir. Harçların üretiminde çimento ve MK malzemelerine ek olarak TS EN 196-1'e [10] uygun standart kum ve içme suyu kullanılmıştır.
Çalışmada kullanılan malzemelerin literatürde bulunan kimyasal özellikleri ise Tablo 1'de verilmiştir.

TABLO I

KULLANILAN MALZEMELERIN KIMYASAL (XRF) KOMPOZISYONU

\begin{tabular}{|c|c|c|c|c|c|c|c|c|c|}
\hline $\begin{array}{l}\text { Oksit } \\
\text { (\%) } \\
\text { CEM }\end{array}$ & $\begin{array}{l}\mathrm{Si} \\
\mathrm{O}_{2}\end{array}$ & $\begin{array}{l}\mathrm{Al}_{2} \\
\mathbf{O}_{3}\end{array}$ & $\begin{array}{l}\mathrm{Fe}_{2} \\
\mathrm{O}_{3}\end{array}$ & $\begin{array}{l}\text { Mg } \\
\text { O }\end{array}$ & $\begin{array}{l}\mathrm{Na}_{2} \\
\mathrm{O}\end{array}$ & $\begin{array}{l}\mathbf{K}_{2} \\
\mathbf{O}\end{array}$ & $\begin{array}{l}\text { SO } \\
3\end{array}$ & $\begin{array}{l}\mathrm{Ca} \\
\mathrm{O}\end{array}$ & $\begin{array}{l}\text { K.K } \\
\cdot\end{array}$ \\
\hline $\begin{array}{l}\text { II/B-M } \\
32.5 \mathrm{R} \\
{[7]}\end{array}$ & $\begin{array}{l}19 . \\
4\end{array}$ & 4.85 & 3.12 & 1.89 & 0.29 & $\begin{array}{l}0.7 \\
3\end{array}$ & $\begin{array}{l}2.5 \\
6\end{array}$ & $\begin{array}{l}54 . \\
22\end{array}$ & $\begin{array}{l}12.3 \\
5\end{array}$ \\
\hline $\begin{array}{l}\text { CEM I } \\
42.5 \mathrm{R} \\
{[4]}\end{array}$ & $\begin{array}{l}19 . \\
70\end{array}$ & 5.39 & 2.64 & 1.42 & 0.26 & $\begin{array}{l}0.8 \\
4\end{array}$ & $\begin{array}{l}3.2 \\
5\end{array}$ & $\begin{array}{l}62 . \\
56\end{array}$ & 3.55 \\
\hline $\begin{array}{l}\text { Kaolin } \\
{[8]}\end{array}$ & $\begin{array}{l}51 . \\
3\end{array}$ & 32.6 & 1.1 & 0.3 & 0.2 & 0.3 & - & 0.1 & 13.0 \\
\hline $\begin{array}{l}\text { Metak } \\
\text { aolin } \\
\text { [9] }\end{array}$ & $\begin{array}{l}51 . \\
8\end{array}$ & 45.8 & 0.35 & 0.03 & 0.13 & $\begin{array}{l}0.0 \\
6\end{array}$ & - & $\begin{array}{l}0.0 \\
1\end{array}$ & 0.91 \\
\hline
\end{tabular}

\section{Kaolin Malzemesine Uygulanan Analizler}

Kaolinin içyapısında bulunan fazların tespiti amacıyla Afyon Kocatepe Üniversitesi, Teknoloji Uygulama ve Araştırma Merkezinde XRD analizi, Bruker marka D8 Advance cihazında yapılırken, kaolinin termal davranışlarının belirlenmesi amacıyla da aynı merkezde DTA-TG analizleri yapılmıştır. DTA/TG analizlerinde örnekler hava ortamında ve $5{ }^{\circ} \mathrm{C} /$ dak. pişirme hızında deneye tabi tutulmuşlardır.

\section{Puzolanik Aktivite Deneyleri}

Çimento harc1 üretiminde kullanılacak olan metakaolin malzemesinin en iyi puzolanik aktivite göstereceği sinterleme sıcaklığının belirlenmesi amacıyla, kaolin kili ağırlıkça \% 20 oranında su ile hobart mikserde karıştırılmış ve $5 \mathrm{~cm}$ çapındaki silindir metal kalıp yardımıyla kaolin kili elle şekillendirilmiştir. Şekillendirilen kaolin kili örnekleri 2.5 ${ }^{\circ} \mathrm{C} / \mathrm{dk}$. pişirme hızında 600-700-800-900 ve $1000{ }^{\circ} \mathrm{C}$ 'de olmak üzere beş farklı sıcaklıkta ve son sıcaklıklarda bir saat süre ile laboratuvar tipi firında kalsine edilerek metakaoline dönüştürülmüştür. Daha sonra metakaolin malzemeleri yine laboratuvar tipi bilyeli değirmende tane boyutu maksimum 250 $\mu \mathrm{m}$ oluncaya kadar ögütülmüştür.

Puzolanik aktivite deneyleri ile ilgili olarak iki farklı standart bulunmaktadır. Bunlar TS EN 450 [14] ve ASTM C 618'dir [15]. Çalışmamızda literatürde daha yaygın olarak kullanılan standart yönteminin kullanılması düşünülmüş ve deneylerde ASTM C 618 [15] nolu standarda göre örnekler hazırlanmıştır. Bağlayıcı malzeme olarak Afyon çimento fabrikası tarafından üretilen CEM I $42.5 \mathrm{R}$ tipi çimento, dolgu malzemesi olaraksa Limak çimento fabrikası tarafindan üretilen standart kum (silis kumu) kullanılmıştır. Harçların hazırlanması sırasında beş farklı sıcaklıkta kalsine edilen metakaolin örnekleri ayrı ayrı deneylerde kullanılmış ve en iyi puzolanik aktivite özellikleri gösteren metakaolin örneklerinin belirlenmesine çalışılmıştır. Örneklerin puzolanik aktivitelerinin belirlenmesinde 7 günlük örnekler 
kullanılmıştır. Puzolanik aktivite deneylerinde kullanılan malzemeler ve miktarları Tablo 2'de verilmiştir.

TABLO II

KULLANILAN MALZEMELERIN KIMYASAL (XRF) KOMPOZISYONU

\begin{tabular}{|c|c|c|c|c|c|c|}
\hline Numune & $\begin{array}{l}\text { Çimento } \\
\text { (gr) }\end{array}$ & $\begin{array}{l}\text { Kum } \\
\text { (gr) }\end{array}$ & $\begin{array}{l}\text { Metakaolin } \\
\text { (MK) (gr) }\end{array}$ & $\begin{array}{l}\text { MK } \\
\text { sinterleme } \\
\text { sicaklığı }\left({ }^{\circ} \mathrm{C}\right)\end{array}$ & $\underset{\mathbf{( g r )}}{\operatorname{Birym}}$ hacim ağrrlık $\left(\mathrm{kg} / \mathrm{m}^{\mathrm{a}}\right)=$ & $\left(\frac{w_{1}}{w_{3}-w_{2}}\right)$ \\
\hline Referans & 500 & 1375 & - & - & 242 & \\
\hline 600 & 400 & 1375 & 100 & 600 & 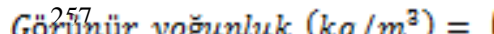 & $w_{1}$ \\
\hline 700 & 400 & 1375 & 100 & 700 & 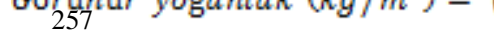 & $w_{1}-w_{2}$ \\
\hline 800 & 400 & 1375 & 100 & 800 & 257 & \\
\hline 900 & 400 & 1375 & 100 & 900 & $\left(W_{3}-W_{1}\right)$ & \\
\hline 1000 & 400 & 1375 & 100 & 1000 & Su remme $(\%)=\left(\frac{3}{w}\right) \times 100$ & \\
\hline
\end{tabular}

MK ikameli çimento harç örnekleri TS EN 196-1 [10] nolu standarda göre Tablo 3'de verilen reçeteye göre 40 x 40 x 160 mm'lik metal harç kalıplarına vibrasyon yöntemiyle yerleştirilmiştir. Bir gün sonra kalıplardan alınan harç örneklerine ilgili testlerin yapılacağı günlere kadar 7 ve 28 günlük su kürü uygulanmıştır.

TABLO III

HAZIRLANAN ÖRNEKLER VE KARIŞIM ORANLARI

\begin{tabular}{|c|c|c|c|c|c|c|c|}
\hline $\begin{array}{c}\text { Harç } \\
\text { Grubu }\end{array}$ & Numune & $\begin{array}{c}\text { Çimento } \\
\text { (32.5 R) } \\
\text { (gr) }\end{array}$ & $\begin{array}{c}\text { Çimento } \\
\text { (42.5 R) } \\
\text { (gr) }\end{array}$ & $\underset{\text { (gr) }}{\text { Kum }}$ & $\begin{array}{c}\text { Metakaolin } \\
\text { (MK) (gr) }\end{array}$ & $\begin{array}{c}\text { Su } \\
(\mathrm{gr})\end{array}$ & $\begin{array}{l}\text { Kür } \\
\text { Süresi } \\
\text { (gün) }\end{array}$ \\
\hline RA7 & Referans & 450 & - & 1350 & - & 225 & 7 \\
\hline RB7 & Referans & - & 450 & 1350 & - & 225 & 7 \\
\hline RA28 & Referans & 450 & - & 1350 & - & 225 & 28 \\
\hline RB28 & Referans & - & 450 & 1350 & - & 225 & 28 \\
\hline 10MKA7 & $\% 10 \mathrm{MK}$ & 405 & - & 1350 & 45 & 230 & 7 \\
\hline 20MKA7 & $\% 20 \mathrm{MK}$ & 360 & - & 1350 & 90 & 235 & 7 \\
\hline 10MKB7 & $\% 10 \mathrm{MK}$ & - & 405 & 1350 & 45 & 230 & 7 \\
\hline 20MKB7 & $\% 20 \mathrm{MK}$ & - & 360 & 1350 & 90 & 235 & 7 \\
\hline 10MKA28 & $\% 10 \mathrm{MK}$ & 405 & - & 1350 & 45 & 230 & 28 \\
\hline 20MKA28 & $\% 20 \mathrm{MK}$ & 360 & - & 1350 & 90 & 235 & 28 \\
\hline $10 \mathrm{MKB} 28$ & $\% 10 \mathrm{MK}$ & - & 405 & 1350 & 45 & 230 & 28 \\
\hline 20MKB28 & $\% 20 \mathrm{MK}$ & - & 360 & 1350 & 90 & 235 & 28 \\
\hline
\end{tabular}

\section{Uygulanan Testler}

Kür işlemi tamamlanan örneklerin fiziksel özellikleri Arşimet prensibine göre belirlenerek; su emme, görünen porozite, birim hacim ağırlık ve görünür yoğunluk değerleri belirlenmiştir. Örneklerin fiziksel özelliklerinin belirlenmesi sırasında; örnekler su tankından alınarak, su içerisinde asılı ağırlıkları $\left(\mathrm{W}_{2}\right)$ ve suya doygun yüzey kuru ağırlıkları $\left(\mathrm{W}_{3}\right)$ belirlenecektir. Ardından ilgili örnekler etüvde değişmez ağılığa gelinceye kadar kurutulacaktır $\left(\mathrm{W}_{1}\right)$. Bu değerler yardımıyla örneklerin görünen porozite, birim hacim ağırlık ve görünür yoğunluk değerleri TS EN 772-4'e [16] göre su emme değerleri ise TS EN 771-1'e [17] göre ve aşağıda verilen eşitlikler yardımıyla (Eşitlik $1-4$ ) hesaplanmıştır. Daha sonra örneklerin ultrases geçiş süreleri ölçülmüş ve ardından eğilme ve basinç mukavemeti deneyleri TS EN 196-1'e [10] göre yürütülmüştür. $\mathrm{Bu}$ standarda göre örnekler, üç noktalı eğilme deneyinde kırılmış ve ikiye ayrılan her parçaya basınç dayanım

\section{BULGULAR VE TARTIŞMA}

testi uygulanmıştır.

$$
\text { Görünen porozite }(\%)=\left(\frac{W_{3}-W_{1}}{W_{3}-W_{2}}\right) \times 100
$$

\section{Kaoline ait XRD ve DTA/TG Analizleri}

Kaolin malzemesine ait XRD analizinden elde edilen verilere göre kaolinde; kuvars, kaolinit ve illit gibi minerallerin varlığı tespit edilmiştir (Şekil 1).
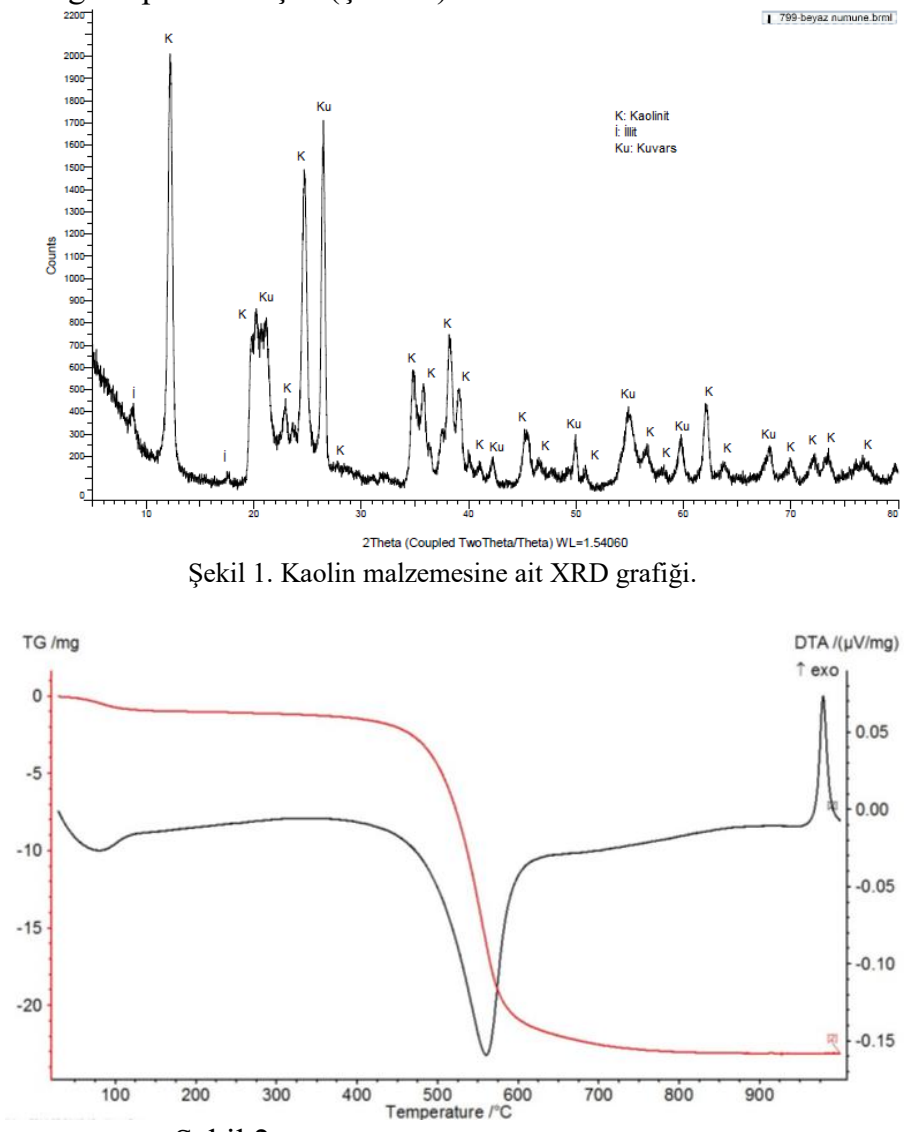

Şekil 2. Kaolin malzemesine ait DTA/TG grafiği.

Kaolin Kaolin malzemesinin termal davranışlarının belirlenebilmesi amacıyla, kaolin örneğine DTA-TG analizleri yapılmıştır. Analizlerden elde edilen veriler Şekil 2'de gösterilmiştir. Verilen grafikte görüldüğü üzere kaolin kili termodinamik olarak $567{ }^{\circ} \mathrm{C}$ 'de endotermik pik göstererek metakaoline dönüşüm yapmıştır. DTA verilerine göre, 978 ${ }^{\circ} \mathrm{C}$ 'de ise ekzotermik pik oluşumu gözlenmiş ve bu sıcaklıktan sonra malzemede kristal yapıların artacağı düşünülmektedir. 
TG analiz verileri incelendiğinde ise kaolin kilinin $900{ }^{\circ} \mathrm{C}$ 'de ki kızdırma kaybı değerinin \% 11.52 olduğu belirlenmiştir.

\section{Puzolanik Aktivite Deneyleri}

Puzolanik aktivite deneylerinden elde edilen veriler Şekil 3'de gösterilmiştir. En ideal sinterleme sıcaklığının belirlenmesinde basınç dayanım değerleri baz alınmıştır. Bununla birlikte bir başka mekanik özelliklerden olan eğilme dayanımı değerleri de yine Şekil 3 (b)'de gösterilmiştir. Grafiklerde de görüldüğü üzere MK katkılı harç örneklerinin büyük çoğunluğunda $\left(800{ }^{\circ} \mathrm{C}\right.$ hariç) referans örneklere göre daha yüksek basınç dayanım değerleri elde edilmiştir. En yüksek basınç dayanım değerleri, $900^{\circ} \mathrm{C}$ 'de kalsine edilen MK katkılı örneklerde 40.4 MPa (Şekil 3a) olarak elde edilirken, aynı örneklerin eğilme dayanımları 11.5 MPa (Şekil 3b) olarak elde edilmiştir. Dolayısıyla bu aşamadan sonra çimentoya ikame edilecek MK malzemesine uygulanacak olan sinterleme sıcaklığının $900{ }^{\circ} \mathrm{C}$ olmasına karar verilmiştir.
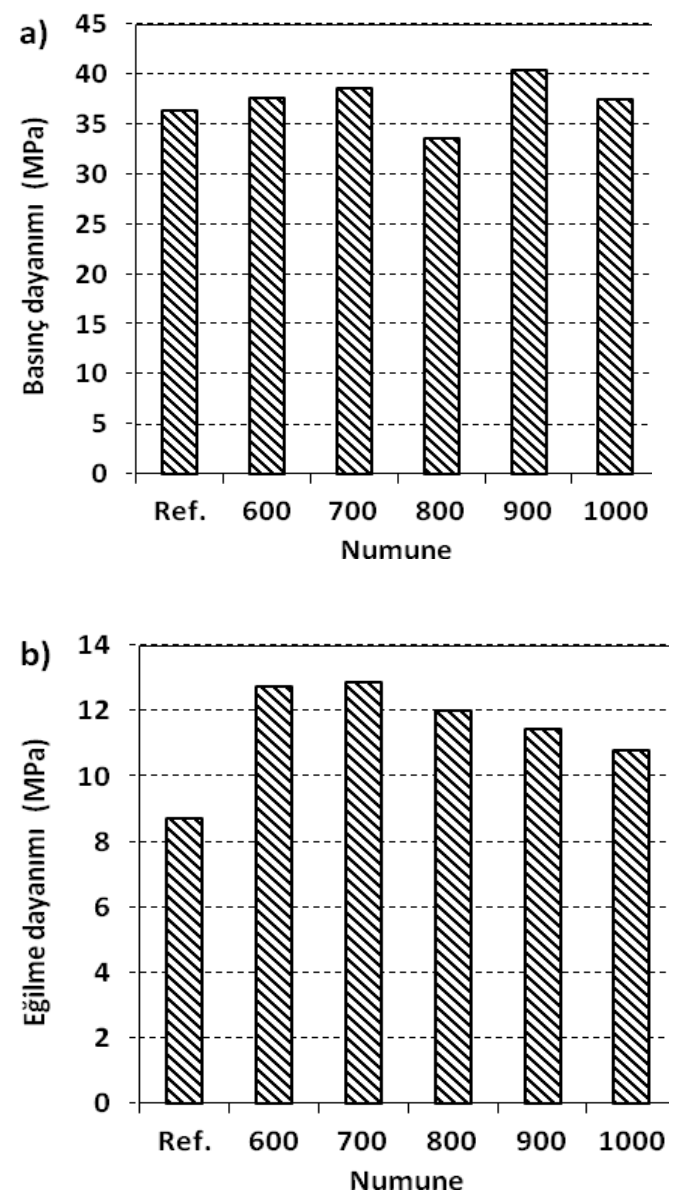

Şekil 3. Puzolanik aktivite deneyinde kullanılan harçların mekanik özellikleri.

\section{Harçların Fiziksel ve Mekanik Özellikleri}

Çalışmada üretilen harçlardan elde edilen veriler bu bölümde sunulmuştur. Örneklerin fiziksel özelliklerinden olan görünen porozite oranları Şekil 4'de gösterilmiştir. Görünen porozite oranları incelendiğinde örneklere uygulanan kür süresinin uzaması ile porozite oranlarında düşüşler gerçekleşmiştir. Kür süresinin artması ile birlikte çimento bünyesinde daha fazla C-S-H ürünü oluşması beklendiğinden dolayı harçların porozite oranlarının düşmesi normal karşılanmalıdır. MK ikameli harçlarda, B çimentosu kullanılması durumunda ise daha yüksek porozite oranlarının ortaya çıktığı gözlenmiştir. Referans harçlarında ise B çimentosu kullanılan örneklerde görünen porozite bir miktar azalmıştır (Şekil 4b).

10MKA7 ve 10MKA28 kodlu harçlarda birbirine yakın porozite oranları elde edilirken, diğer tüm örneklerde 28 günlük kür uygulaması harçların porozite değerlerini azaltmıştır (Şekil 4a). Örnek grupları içerinde 7 gün kür uygulanan MK ikameli harçlarda kür süresinin artması ile porozite oranları artarken; A çimentolu 28 günlük harçlarda MK katkısı arttıkça porozite azalmış, B çimentolu harçlarda ise katkı oranı arttıkça porozite oranları artmıştır. En yüksek porozite oranları \% 28.2 ile 20MKB7 örneklerinden elde edilirken, en düşük porozite oranları \% 8 ile 20MKA28 örneklerinden elde edilmiştir.
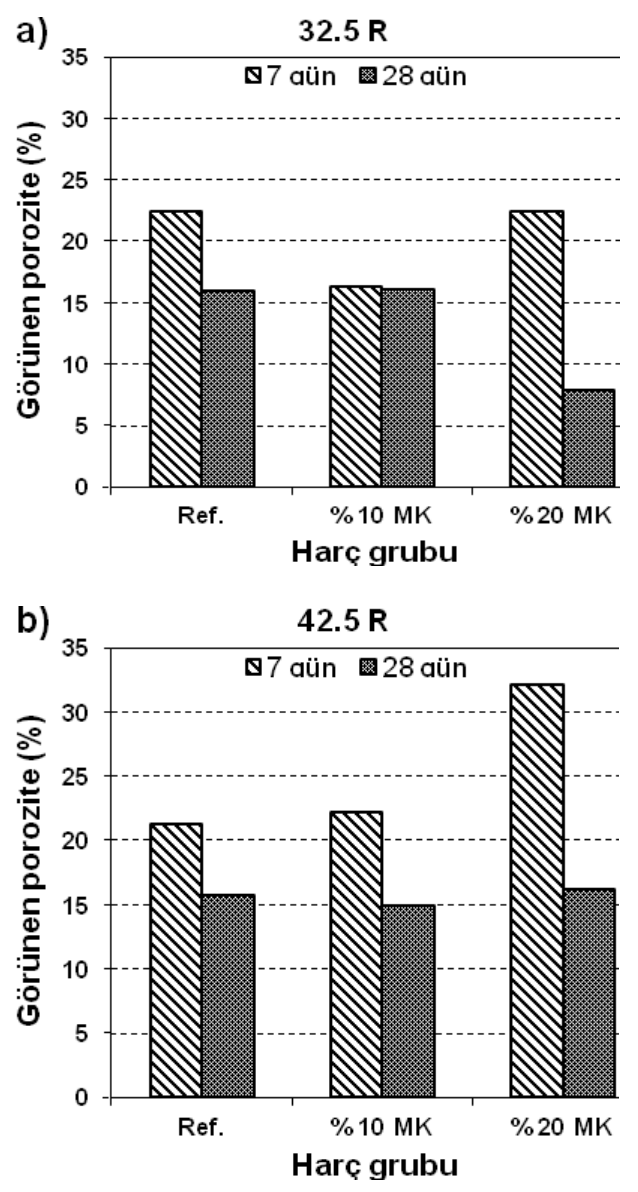

Şekil 4. Harçların görünen porozite oranları.

Çimento harçlarının su emme oranları Şekil 5'de 
gösterilmiştir. Grafiklerde de görüleceği üzere su emme oranları, görünen porozite oranlarından elde edilen verilerle benzer eğilimler göstermiştir. En fazla su emme oranları \% 18.9 ile 20MKB7 örneklerinden elde edilirken, en düşük su emme oranlar1 \% 3.8 ile 20MKA28 örneklerinden elde edilmiştir.
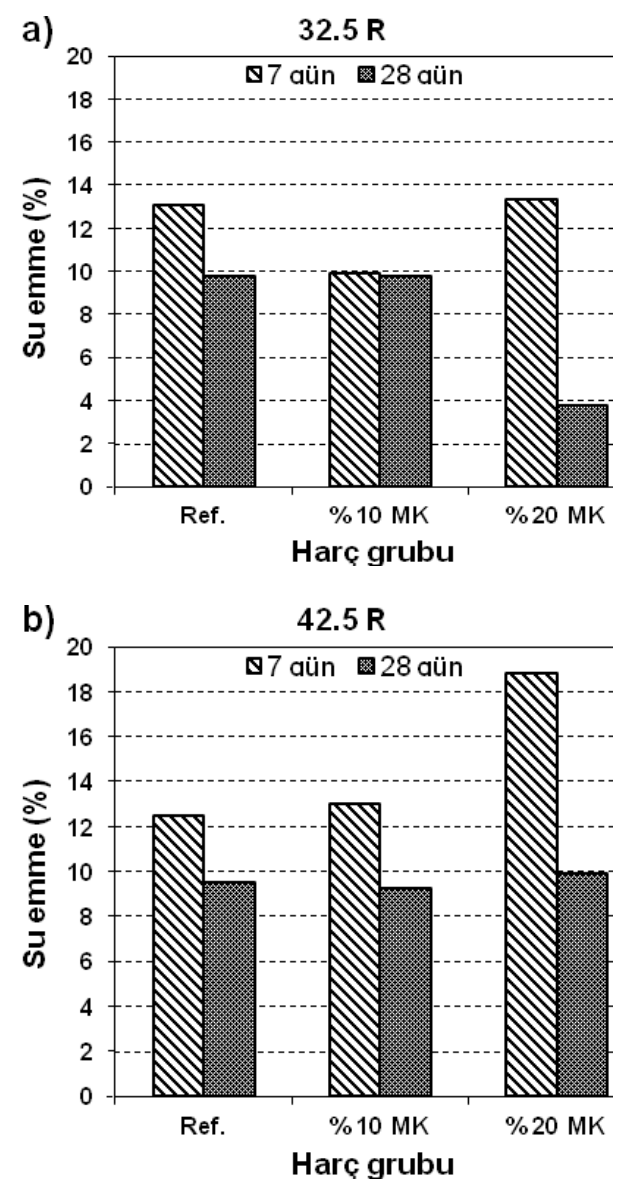

Şekil 5. Harçların görünen su emme oranları

Çimento harçlarının yoğunluk değerleri Şekil 6 ve Şekil 7 'de gösterilmiştir. Örneklere uygulanan kür süresinin artması ile birlikte bünyede reaksiyon ürünlerinin artmasından dolayı harçların birim hacim ağırlıklarının arttığı belirlenmiştir. A çimentosu ile üretilen harçlardan $2109.4 \mathrm{~kg} / \mathrm{m}^{3}$ ile en yüksek birim hacim ağırlıklar RA28 örneklerinden elde edilirken; B çimentosu ile üretilen harçlarda $2119.8 \mathrm{~kg} / \mathrm{m}^{3}$ ile en yüksek birim hacim ağırlıklar RB28 örneklerinden elde edilmiştir. MK katkılı örneklerde ise her iki tip çimento sınıfinda da \% $10 \mathrm{MK}$ katkılı örneklerin daha yüksek yoğunluk değerlerine sahip oldukları gözlenmiştir (Şekil 6).

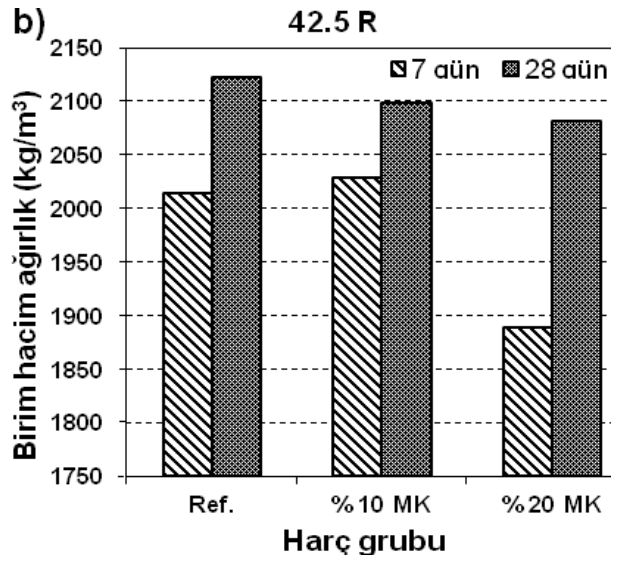

Şekil 6. Harçların birim hacim ağılık değerleri
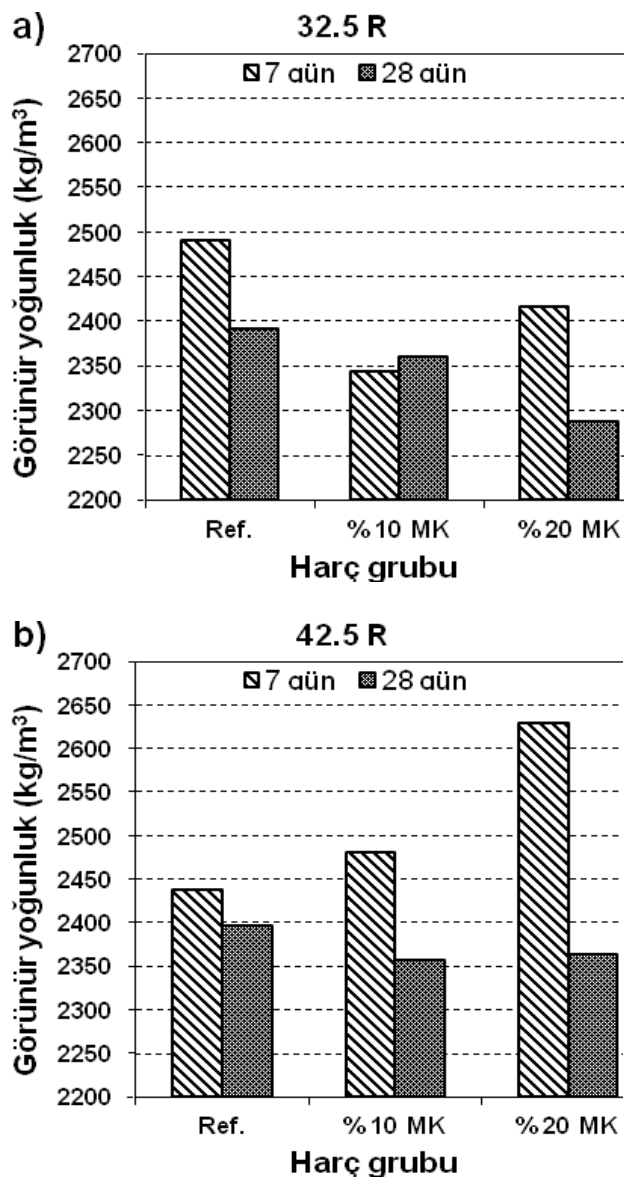

Şekil 7. Harçların görünür yoğunluk değerleri.

MK katkılı örneklerde kullanılan çimentonun yüksek dayanımlı olması durumunda, örneklerin görünür yoğunları daha yüksek seviyelerdedir. Dolayısıyla harç üretiminde B çimentosunun kullanılması durumunda, MK katkılı harçların referans örneklerden daha yüksek görünür yoğunluk değerlerine sahip oldukları gözlenmiş̧ir (Şekil 7). Harçlara uygulanan kür süresinin arttırılması örneklerin görünen porozitesini azaltmış, dolayısıyla porozitesi azalan örneklerin birim hacim ağırlıkları artmıştır. Görünür yoğunluk değerlerinde ise uzayan kür süresi ile birlikte yoğunluk 
değerlerinin azaldığı görülmüsştür. Örnek bünyesinde porozite oranının azalmasına rağmen görünür yoğunluk değerlerindeki bu düşüşlerin bünyede bulunan MK katkısının yüksek oranda reaksiyonlar gerçekleştiremediği ve bu nedenle yoğunluk değerlerinin daha düşük oranlarda kaldığı tahmin edilmektedir.

A çimentosunun kullanıldığı harçlarda karışımlara eklenen MK katkısı örneklerin eğilme dayanımlarında düşüşlere neden olmuştur (Şekil 8a). B çimentosunun kullanıldığı örneklerde ise eğilme dayanımı değerlerine $\mathrm{MK}$ katkısının etkisi net değildir ve değişkendir (Şekil 8b).

A çimentolu örneklerde, harçların basınç dayanımları MK katkı oranının ve kür süresinin artması ile birlikte artarken, referans örneklerde en düşük basınç dayanım değerleri elde edilmiştir (Şekil 9a). 7 günlük B çimentolu örneklerde $\% 10$ MK katkılı harçlarda, 28 günlük örneklerde ise \% $20 \mathrm{MK}$ katkılı örneklerde en yüksek basınç dayanım değerleri elde edilmiştir. Basınç dayanım değerleri bir arada değerlendirildiğinde; A çimentosu ile \% 20 MK ve B çimentosu ile \% $10 \mathrm{MK}$ malzemeleri bir arada kullanıldığında en yüksek basınç dayanım değerleri sırasıyla $47.9 \mathrm{MPa}$ ile 20MKA28 ve 42.6 MPa ile 10MKB7 örneklerinden elde edilmiştir (Şekil 9a ve Şekil 9b). Daha önceden yapılan çalışmalarda da çimentoya ağırlıkça \% 10 - \% 20 oranlarında MK ikamesinin basınç dayanımları arttırdığı [13], bununla birlikte MK ile üretilen harç ve betonlarda özellikle ilk 14 gün içinde mekanik özelliklerin daha etkili bir şekilde artışlar gösterdiği belirtilmiştir [4].
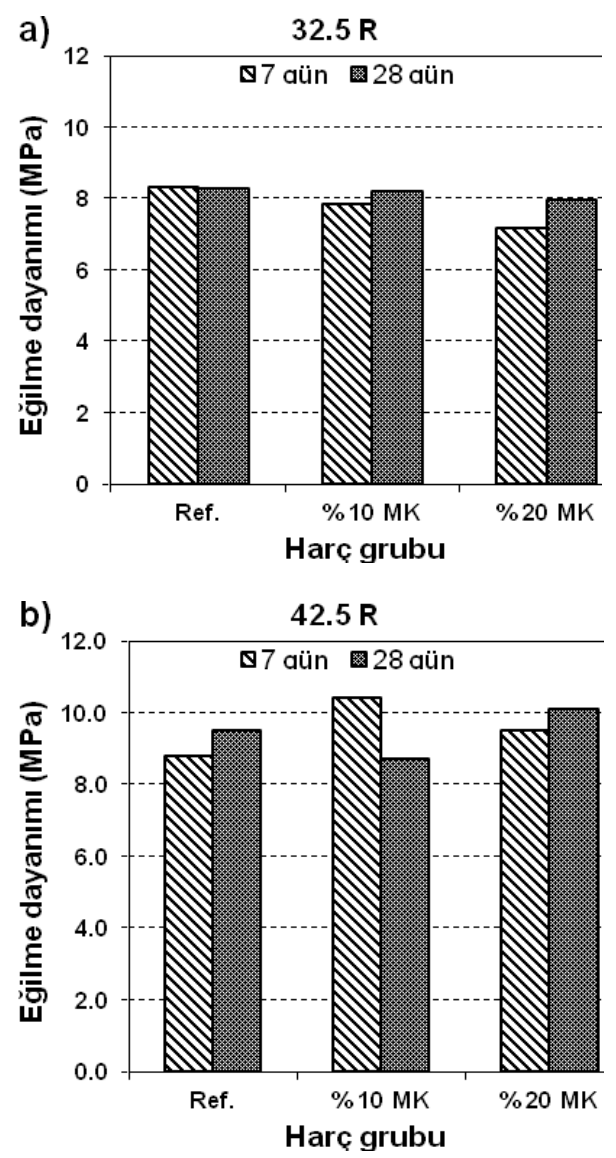

Şekil 8. Harçların eğilme dayanımı değerleri.
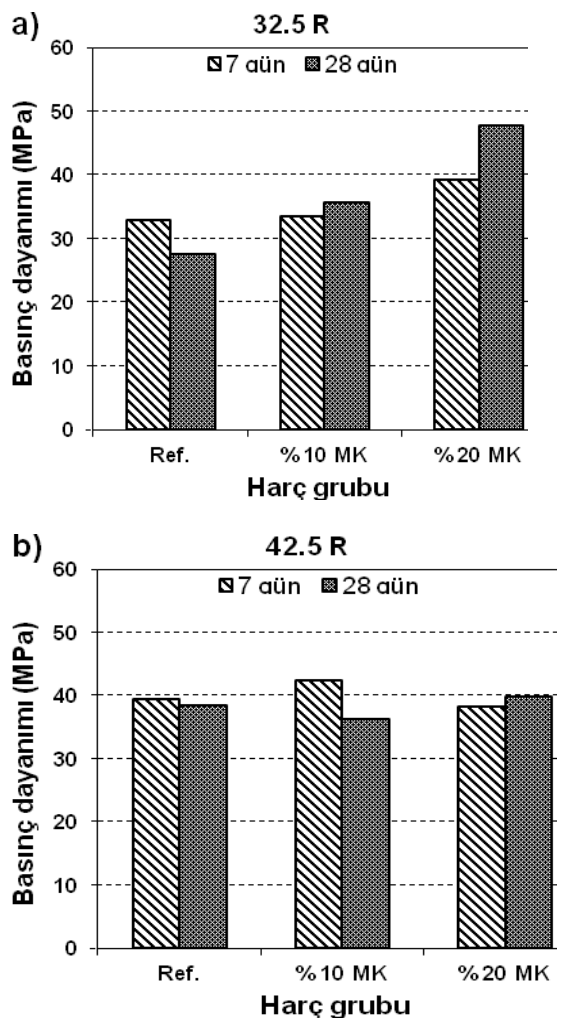

Şekil 9. Harçların basınç dayanım değerleri.

Çimento harçlarında bulunan MK katkısının ultrases değerlerini etkilediği ve B çimentolu örneklerde MK katkısının artması ile birlikte örneklerin ultrases hızı değerlerinin arttığ belirlenmiştir. A çimentolu örneklerde ise MK katk1 oranındaki artışların ultrases değerlerini düşürdüğü tespit edilmiştir. 7 günlük örneklerde $\% 10 \mathrm{MK}$ katkılı harçlarda en yüksek değerler elde edilirken, 28 günlük harçlarda en yüksek değerler referans örneklerden elde edilmiştir (Şekil 10a ve Şekil 10b).

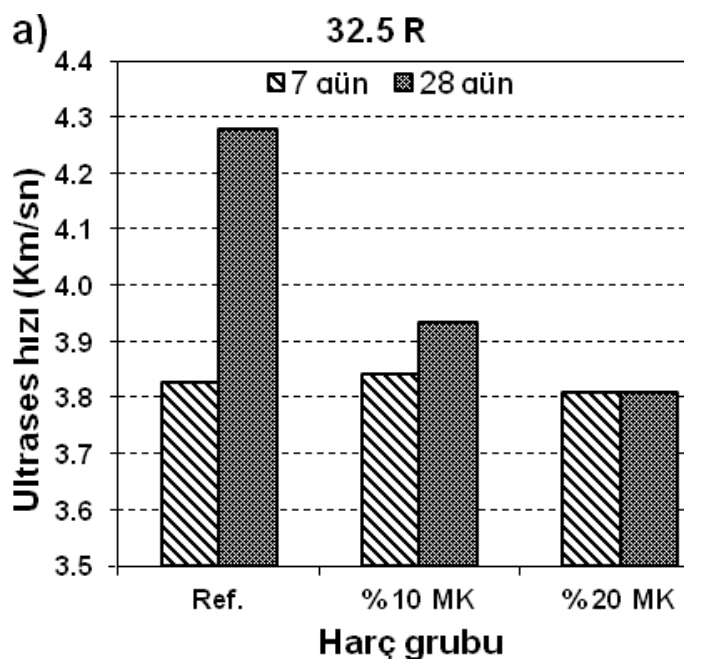




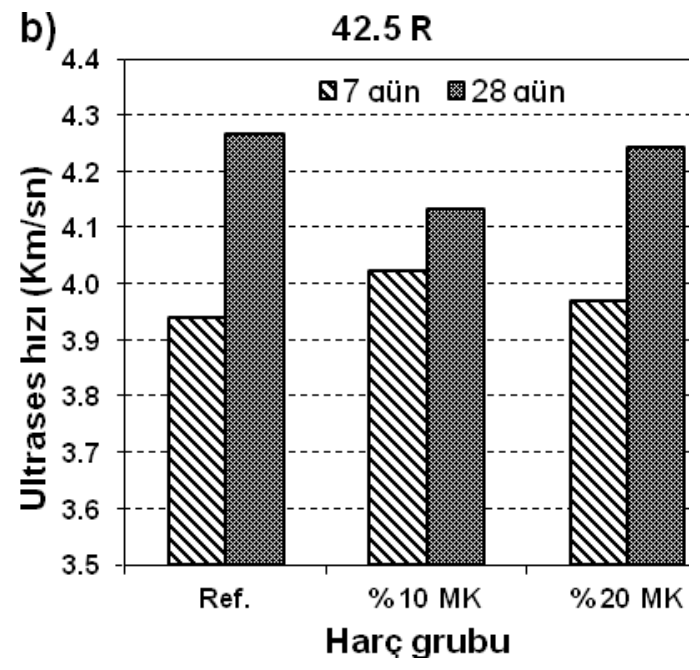

Şekil 10. Harçların ultrases hızı değerleri.

\section{SONUÇLAR}

İki farklı çimento sınıfı ve metakaolin ikamesinin çimento harç özelliklerinde meydana getirdiği değişikliklerin araştırıldığı bu çalışmadan elde edilen verilere göre;

- Kaolin kiline uygulanacak ideal sinterleme sıcaklığının $900{ }^{\circ} \mathrm{C}$ olduğu ve bu sicaklıkta sinterlenmiş metakaolin örneklerinin en yüksek basınç dayanım değerlerini verdiği gözlenmiştir.

- 10MKA7 ve 10MKA28 kodlu harçlarda birbirine yakın porozite oranları elde edilirken, diğer tüm örneklerde 28 günlük kür uygulaması ile harçların porozite değerleri azalmıştır.

- MK ikameli harçlarda, B çimentosu kullanılması durumunda daha yüksek porozite oranlarının ortaya çıktı̆̆ 1 , referans harçlarında ise $\mathrm{B}$ çimentosu kullanılan örneklerde görünen porozitenin bir miktar azaldığ 1 gözlenmiştir. A çimentolu 28 günlük harçlarda MK katkısı arttıkça porozite azalmış, B çimentolu harçlarda ise katkı oranı arttıkça porozite artmıştır.

- Harçların su emme oranları, görünen porozite oranlarından elde edilen verilerle benzer eğilimler göstermiştir.

- Örneklere uygulanan kür süresinin artması ile birlikte bünyede reaksiyon ürünlerinin artmasından dolayı harçların birim hacim ağırlıkları artmıştır.

- MK katkılı örneklerde her iki tip çimento sınıfinda da \% 10 MK katkılı örneklerin daha yüksek yoğunluk değerlerine sahip oldukları gözlenmiş̧ir

- MK katkılı örneklerde kullanılan çimentonun yüksek dayanımlı olması durumunda, örneklerin görünür yoğunlarının daha yüksek seviyelerde olduğu ve bu nedenle B çimentosunun kullanılması durumunda, MK katkılı harçların referans örneklerden daha yüksek görünür yoğunluk değerlerine sahip oldukları gözlenmiştir

- Harçlara uygulanan kür süresinin arttırılması örneklerin görünen porozitesini azaltmış, dolayısıyla porozitesi azalan örneklerin birim hacim ağırlıkları artmıştır. Görünür yoğunluk değerlerinde ise uzayan kür süresi ile birlikte yoğunluk değerlerinin azaldığ 1 görülmüştür.

- A çimentosunun kullanıldı̆̆ harçlarda MK katkısı eğilme dayanımlarını düşürürken; $\mathrm{B}$ çimentosunun kullanıldığı örneklerde eğilme dayanımına MK katkısının etkisi net değildir.

- A çimentosu ile \% $20 \mathrm{MK}$ ve B çimentosu ile \% 10 MK malzemelerinin bir arada kullanılması durumunda örneklerden en yüksek basınç dayanım değerleri elde edilmiştir.

\section{TEŞEKKÜR}

Yazarlar bu çalışmayı maddi olarak destekleyen Afyon Kocatepe Üniversitesi Bilimsel Araştırma Projeleri Koordinasyon Birimi'ne (AKÜ BAPK Proje No: 14.HIZ.DES.69) teşekkür eder.

\section{KAYNAKLAR}

[1] E. Başpınar, M. Kuşçu, "Karaçayır (Uşak) kaolen yatağı kaolen üretim yöntemi”, SDUGEO E-dergi, ss. 27-35, (http://edergi.sdu.edu.tr/index.php/sdugeo/article/viewFile/3122/2715), 15.11.2014.

[2] A.G. Türkmenoğlu, A. Tankut, "Use of tuffs from central Turkey as admixture in pozzolanic cements: Assessment of their petrographical properties", Cement and Concrete Research, Vol.32, No.4, pp. 629637, 2002.

[3] Ç. Meral, "Use of perlite as a puzzolanic addition in blended cement production", M.E.T.U., Thesis of Master of Science, 2004.

[4] Ş. Yazıcı, D. Anuk, H. Ş. Arel, "Metakaolin Kullanımının Harçların Mekanik Özellikleri Üzerine Etkisi”, S. Ü. Müh. Fak. Derg., Vol.25, No.2, ss. 13-24, 2010.

[5] B. Akçay, Ö. Peker, C. Şengül, M. A., Taşdemir, "Metakaolin İçeren Betonun Kırılma Davranışı", Beton Kongresi, İstanbul, ss. 424-435, 2013.

[6] M.A. Caldarone, K.A. Gruber, R.G. Burg, "High reactivity metakaolin (HRM): a new generation mineral admixture for high performance concrete", Concrete International, Vol.16, No.11, pp.37-40, 1994.

[7] F. Curcio, B.A. DeAngelis, S. Pagliolico, "Metakaolin as a pozzolanic microfiller for high-performance mortars", Cement and Concrete Research, Vol.28, No.6, pp. 803-809, 1998.

[8] X. Qian, Z. Li, "The relationships between stress and strain for highperformance concrete with metakaolin", Cement and Concrete Research, Vol.31, pp, 1607-1611, 2001.

[9] L. Courard, A. Darimont, M. Schouterden, F. Ferauche, X. Willem, R. Degeimbre, "Durability of mortars modified with metakaolin", Cement and Concrete Research, Vol.33, No.9, pp. 1473-1479, 2003.

[10] TS EN 196-1. Çimento Deney Metotları- Bölüm 1: Dayanım (Methods of testing cement - Part 1: Determination of strength) TSE, Ankara Turkey, 2002.

[11] C. Kılınç, S. Satılmış, T. Akakın, "Farklı Oranlarda Mineral Katkı ve Agreganın Alkali Silika Reaksiyonu Üzerine Etkisi”, (http://www.thbb.org/Files/File/[501-510].pdf), 13.03.2015.

[12] J.G.S. Jaarsveld, J.S.J. Deventer, G.C. Lukey, "The effect of composition and temperature on the properties of fly ash- and kaolinitebased geopolymers", Chemical Engineering Journal, Vol.89. No.1-3, pp. 63-73, 2002.

[13] E. Güneyisi, M. Gesoğlu, K. Mermerdaş, "Improving strength, drying shrinkage, and pore structure of concrete using metakaolin", Materials and Structures, Vol.41, pp. 937-949, 2008.

[14] TS EN 450. Betonda Kullanılan Uçucu Kül -Tarifler, Özellikler ve Kalite Kontrolü, (Fly ash for concrete - Definitions, requirements and quality control)TSE. Ankara -Turkey, 1988. 
[15] ASTM C 618. Standart Specification for Coal Fly Ash and Raw or Calcined Natural Pozzolan for Use as a Mineral Admixture in Concrete. Annual Book of ASTM Standart, No. 04.02, 2000.

[16] TS EN 772-4. Kagir Birimler, deney metotları - Bölüm 4: Tabii taskâgir birimlerin toplam ve görünen porozitesi ile bosluksuz ve bosluklu birim hacim kütlesinin tayini (Methods of test for masonry units - Part 4: Determination of real and bulk density and of total and open porosity for natural stone masonry units). TSE. Ankara-Turkey, 2000.

[17] TS EN 771-1. Kagir Birimler, Özellikler- Bölüm 1: Kil kâgir birimler (Tuğlalar) (Specification for masonry units - Part 1: Clay masonry units) TSE. Ankara-Turkey, 2005.

[18] F. Curcio, B. A. De Angelis, S. Pagliolico, "Metakaolin as a pozzolanic microfiller for high-performance mortars", Cement and Concrete Research, Vol.28, No.6, pp. 803-809, 1998. 